\begin{tabular}{cc} 
bentham open & The Open Petroleum Engineering \\
JoussMark & Content list available at: www.benthamopen.com/TOPEJ/ \\
DOI: $10.2174 / 1874834101609010299$ & \\
\hline
\end{tabular}

RESEARCH ARTICLE

\title{
Paleogene-Neogene Cap Rocks and its Relationship with Hydrocarbon Accumulation in the Zhanhua Sag
}

\author{
Chunyan $\mathrm{Wu}^{1, *}$, Jingong Zhang ${ }^{1}$, Wei Xiong ${ }^{2}$, Bo $\mathrm{Li}^{2}$, Yijun $\mathrm{Wang}^{3}$, Jinning Zhang ${ }^{1}$ and Qiang Cui ${ }^{1}$

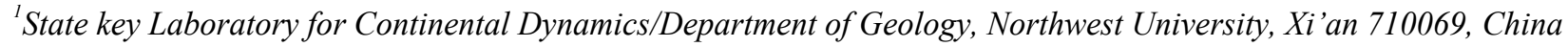 \\ ${ }^{2}$ Geology Scientific Research Institute of Shengli Oilfield Company, Sinopec, Dongying 257015, China \\ ${ }^{3}$ Eastern Geophysical Company Research Institute of Changqing Branch, Xi'an 710021, China
}

Received: April 13, 2016

Revised: November 03, 2016

Accepted: November 10, 2016

\begin{abstract}
To analyse the Zhanhua Paleogene-Neogene cap rocks and its relationship with hydrocarbon accumulation, the seal lithology, the relationship between compaction of argillite rock and its sealing capacity, and its destruction by faults and fractures were studied. The results indicate that there are four types of cap rocks: argillite rock and silty mudstone, microcrystalline carbonate, dense cemented sandstone and dense cemented carbonate. Among these cap rocks, argillite rock is the main type in the Zhanhua Sag. According to the evolutionary characteristics of the argillite rock and its destruction by fractures and faults, the argillite cap can be classified into three categories: porosity cap, fracture transformation cap and the fault transformation cap. Among their sealing capacities, the porosity cap is the best, followed by the fracture transformation cap, and the fault transformation cap is the worst. Through the analysis of the relationship between existing oil \& gas reservoirs and the distribution characteristics of the Paleogene-Neogene cap rocks in the Zhanhua Sag, it was found that the cap combination which was below or above the reservoir together controlled the hydrocarbon accumulation and preservation. It means that the destruction of the cap below or down-dip the reservoir is a necessary condition for hydrocarbon accumulation, and only when the sealing capacity of the cap rock above or up-dip the reservoir is better than that of below or down-dip the reservoir, hydrocarbon could be efficiently stored in reservoirs, thus could be effectively enriched.
\end{abstract}

Keywords: Cap Rock, Fault, Fracture, Hydrocarbon Accumulation, Zanhua Sag.

\section{INTRODUCTION}

Cap is an important factor in the formation and preservation of hydrocarbon, and its quality directly affects the formation, size and preservation of oil and gas reservoirs. In long-term oil and gas exploration and practice, it was realized that among the elements of hydrocarbon accumulation, cap rock plays a key role in petroleum preservation [1 5]. There are three main sealing mechanisms in cap rocks: the physical properties sealing, the pressure sealing and the hydrocarbon concentration sealing. Among them, the pressure sealing can only exist in a mudstone cap under compaction, and the hydrocarbon concentration sealing can only exist in a cap having hydrocarbon potential [6]. However, both the pressure sealing and the hydrocarbon concentration sealing, need certain conditions of the physical properties of the cap. Currently, to evaluate the physical properties of caps, parameters are used as follows: porosity, permeability, density, micro-pore structure, pore throat radius, median pressure mercury pressure, coefficient of variation, displacement pressure, breakthrough pressure, shale content, carbonate content, capping layer thickness, cumulative thickness, sedimentary environment, degree of diagenesis, rock mechanical properties etc. [7 - 14]. All of the above parameters are used to evaluate sealing ability by a consideration of the cap itself [15], but the practice of hydrocarbon exploration shows that a certain range of macro-spread (i.e., the integrity of the cap) is necessary to form an effective seal [16 - 22]. Moreover, as pointed out by Krooss et al. (1986) fractures may change cap rock seal effectiveness; in this case, the sealing capacity depends on the inner vertical seal capacity of the fault [23 - 32].

\footnotetext{
* Address correspondence to this author at the State key Laboratory for Continental Dynamics/Department of Geology, Northwest University, Xi'an 710069, China; Tel: +86 13669226216; E-mails: wcy_gift@sina.cn,wuchunyanbaby@163.com
} 
Furthermore, sealing capacity is dynamically evolving, and it continues to strengthen with the depth increases. In the latter tectonic movements, brittle rock can easily form micro fractures, which weaken its sealing ability [33]. It can be observed that the quality of a cap not only depends on its own sealing characteristics but also on whether it is destroyed by fractures and faults or not. Less attention has been laid on the characteristics of cap rocks in the Zhanhua sag, and Xuetian Li (1992) studied the quality factors of a gas cap in the Jiyang Depression, but he focused on the effects of the sedimentary environment, compaction and diagenesis of the cap itself, rather than its destruction [34]. In this paper, we discuss the seal lithology by flake identifications and mercury intrusion experiments, and then divide the cap types by studying the relationship between the degree of compaction and its capping ability, as well as the damage by faults and fractures. At last, we analyze the relationship between cap and hydrocarbon accumulation, and propose a model about the relevance between argillite rock and hydrocarbon accumulation and preservation. This approach can be used in oil and gas exploration, represents a straightforward and brand-new workflow to be applied in areas of complex.

\section{GEOLOGICAL CHARACTERISTICS OF THE WORK AREA}

The study area is in the Zhanhua Sag located in the northern part of the Jiyang Depression of the Bohai Bay Basin, China (Fig. 1). It is a Cenozoic extensional rift basin. Yinan, Yidong, and Chengdong faults are in the North, Kendong uplift is in the East, and the regional stratigraphic overlap transition to Chenjiazhuang uplift is in the South. The stratigraphy mainly developed during the Paleogene strata (Ek, Es, and Ed stratum), Neogene strata (Ng and Nm stratum) and Quaternary stratum. From the deposition of the Paleogene to the Quaternary, the Zhanhua Sag was mostly buried, and there was only one short-term erosion on the edge in the end stage of the Ed, and the extent of the erosion was less than 100 metres. Mostly, the Zhanhua Sag existed in a tensile stress field since the Paleogene.

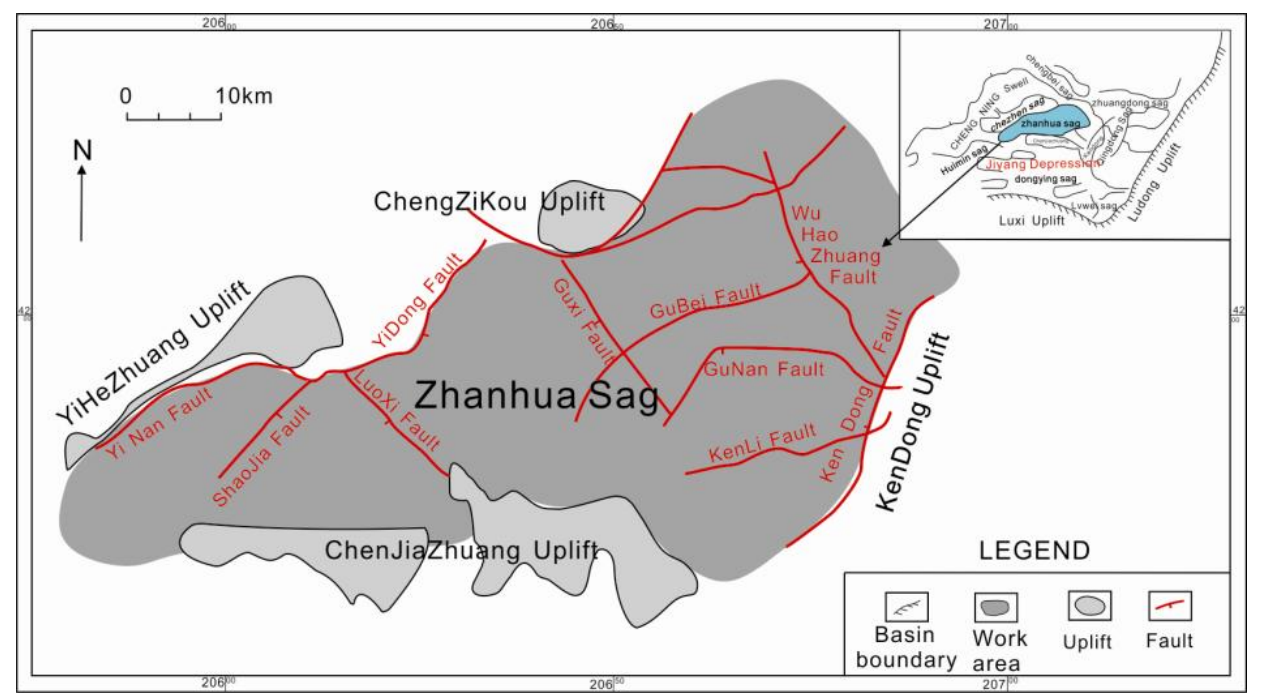

Fig. (1). The location of the basin.

\section{SEAL LITHOLOGY OF PALEOGENE-NEOGENE STRARA}

Considerable researches about the cap lithology have been conducted, and the researchers believed that the common lithologies mainly included cream rock, argillite rock, dense limestone, and evaporites [35 - 37]. However, we conducted flake identifications to investigate the lithology of seal layer using a drill core sample of cap rock obtained in Zhanhua sag, which contains the rock with or without oil, and its interface. In order to reach a better understanding and an improved quantification and prediction of sealing capacity of cap rocks mercury intrusion experiments were carried out on those samples. The results demonstrate that all the breakthrough pressures of rocks containing poor oil are more than $5 \mathrm{MPa}$, which means most of them completely have the abilities to cover hydrocarbon. Therefore, we think the rock free of oil or poor oil could be considered as cap rock under certain preconditions. This approach of judge cap rock turned out to be particularly useful in Zhanhua sag, and can be applied in this paper. Finally, four types of cap rocks are identified in this paper: 


\subsection{Argillite rock and Silty Mudstone}

Fig. (2a) shows that the argillite rock belongs to Es3 stratum of Paleogene is gray-black and the siltstone is gray. It can be clearly noticed that the siltstone contains oil is thick and black in the core. The fluorescent flake of Siltstone show yellow or brown colour, which indicates that it contains oil well. In contrast, the overlying argillite shows yellow or brown fluorescence, even part of this argillite shows bright yellow fluorescence, which indicates that it does not contain oil well (see Fig. 2b). The ingredients of the latter one are clay and debris particles, and its lithology is argillite rock or silty mudstone (see Fig. 2c).

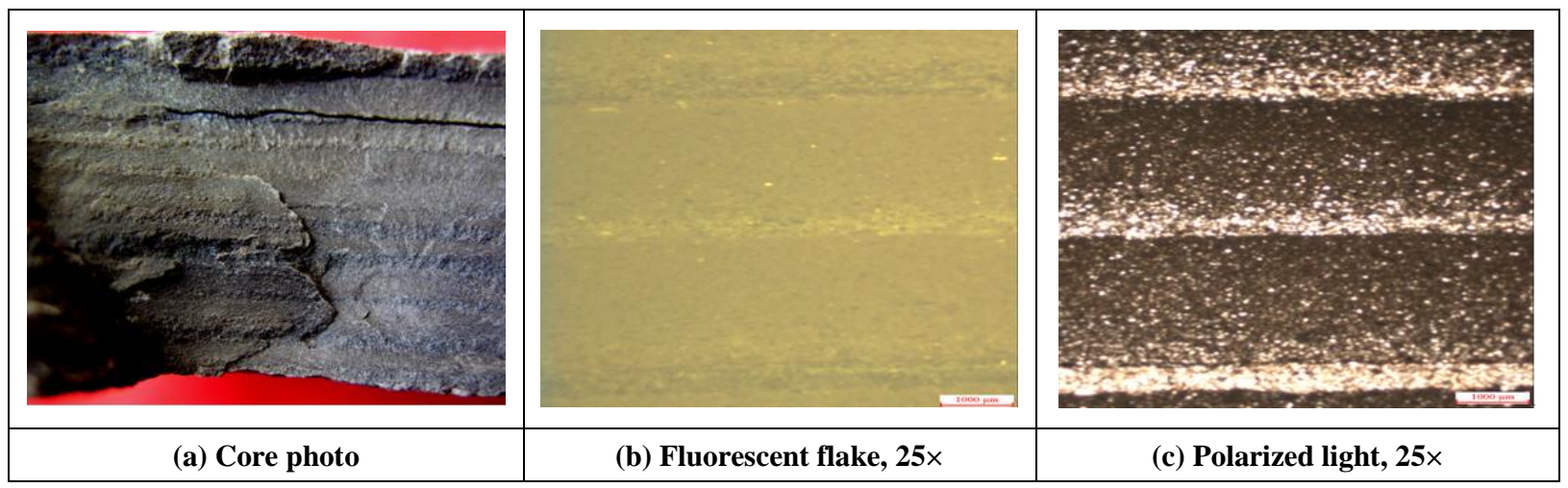

Fig. (2). Argillite rock and silty mudstone, Tjs4o-y-y-2-25, Y160, $3164.85 \mathrm{~m}$.

\subsection{Microcrystalline Carbonate}

Fig. (3a) shows that the lower right side of the core contains oil well, while the upper left side of the core does not contain oil, and it is hard to see differences in lithology from the hand specimen. To analyse different relationships between oil and lithologies, oil slices and casting thin sections are taken from the oil interface. The results show that the oily part is sandstone, and the part of oil-poor is microscopic crystalline carbonate (limestone), which belongs to Es 1 stratum of Paleogene (see Fig. 3b, c).

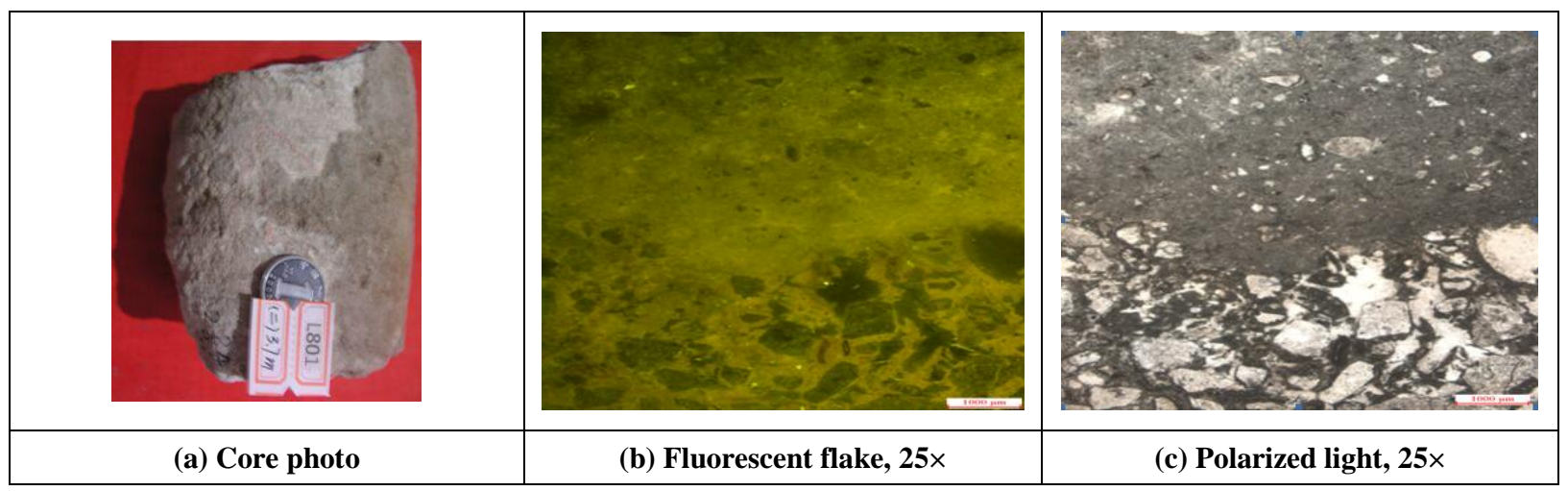

Fig. (3). Microcrystalline carbonate, J11zo, L801, $1691.43 \mathrm{~m}$.

\subsection{Dense Cemented Sandstone}

Sandstone rock of Fig. (4a) belongs to Es3 stratum of Paleogene is hard to find differences in lithology, contrastingly, easily find obvious differences in oiliness by naked eyes. The lower part appears brown containing significant amount of oil, while the upper part appears grey containing less oil. Judged from fluorescent flake, despite similarity of the lithology, the oily part shows yellow-green, and the transition zones of the oily and non-oily shows weak fluorescent colour (see Fig. 4b). In the oily and non-oily parts, the components and shapes of the debris particles are similar, while the cements are different. The oily section has less cement with pore development, the non-oily part has more cement, and majority of the base is carbonate cement (see Fig. 4c). 


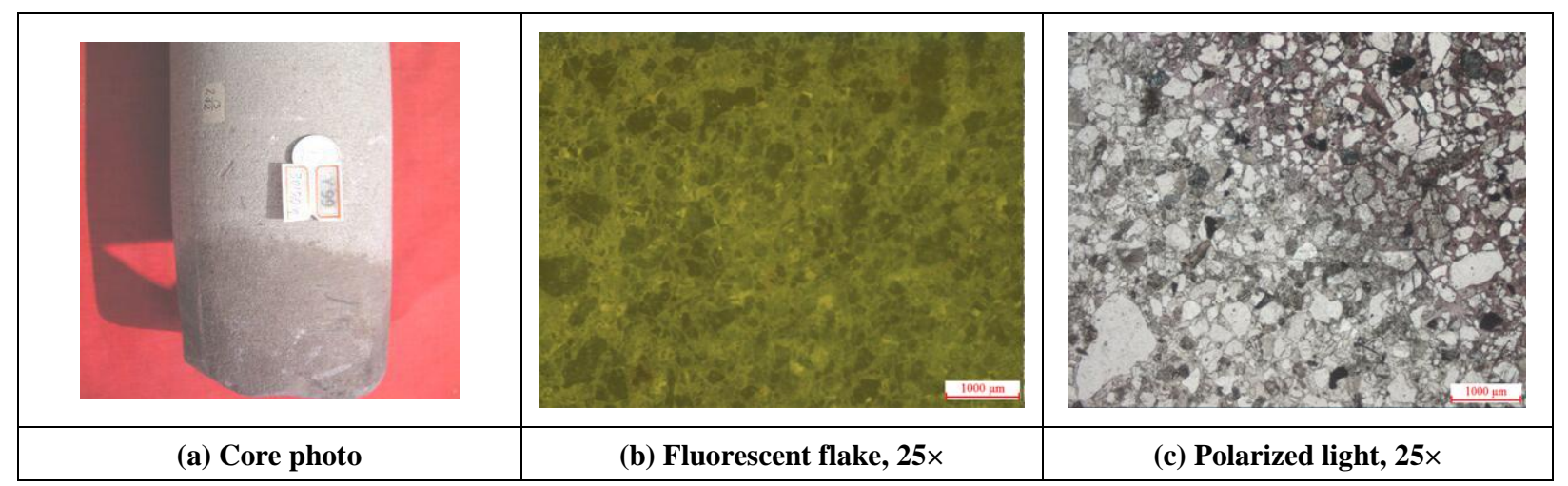

Fig. (4). Dense cemented sandstone, j9oo, Y99, $3150 \mathrm{~m}$.

\subsection{Dense Cemented Carbonate}

Fig. (5a) shows grey carbonate belonging to $\mathrm{Ng}$ stratum of Neogene. There are significant differences in oiliness. The lower part has an oil tie which approximates $6.3 \mathrm{~cm}$. The oily part is brown and the non-oily part is yellow showed from the florescent slices. The components and shapes of the debris particles showed from the casting thin sections are similar in the oily and non-oily points. And the types of cements are different. The oily section has less cement with pore development, the non-oily part has less cement, majority of the base is carbonate cement (see Fig. 5b, c).

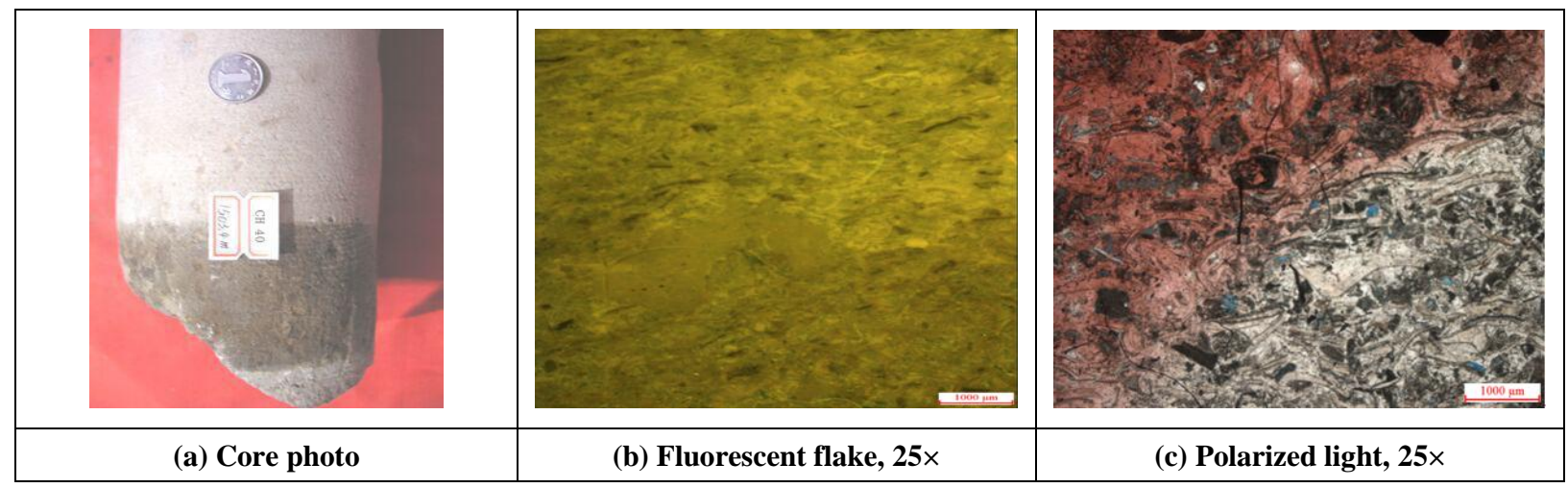

Fig. (5). Dense cemented carbonate, J6zo, CH40, $1503.4 \mathrm{~m}$.

The above mentioned images just represent types of Paleogene-Neogene cap Lithology. In fact, it was found that argillite rock is the main type of Paleogene-Neogene strata in the Zhanhua sag. Because the information of other cap lithologies is incomplete, and the distribution on the plane is discontinuous, this paper focuses on the argillite rock rather than other cap rocks.

\section{CAP TYPES AND DISTRIBUTION}

\subsection{Relationship Between Compaction of Argillite Rock and its Sealing Capacity}

Both the porosity and permeability of the cap of argillite rock decreased and its sealing capacity was enhanced under continuously buried conditions, which demonstrates that the sealing ability is closely related to the degree of compaction [33]. If we ignore the effects of cementation on argillite porosity, the lower porosity of argillite has, the higher degree of compaction it has. According to the porosity of 62 argillite rock samples by Dunxiang Zhang (1979), we added our experimental data, and drew the graph of porosity vs. depth in Jiyang Depression, which well display the relevance between compaction and depth. Fig. (6) shows that argillite porosity decreases with increasing depth, in other words, the degree of compaction increases. According to the variation rate of porosity, the degree of compaction with depth can be classified into four stages:(1) less than $1000 \mathrm{~m}$ in depth, with a porosity greater than $23 \%$ and where the porosity deceases rapidly with increasing depth; (2) depth form 1000 to $2000 \mathrm{~m}$, with porosity ranging from $20 \%$ to $23 \%$ and where the porosity deceases slowly with increasing depth; (3) depth from 2000 to 2700 m, with a porosity from $5 \%$ to $20 \%$ and where the porosity deceases rapidly with increasing depth; (4) deeper than $2700 \mathrm{~m}$, with a porosity 
of less than $5 \%$ and where the porosity deceases very slowly with increasing depth.

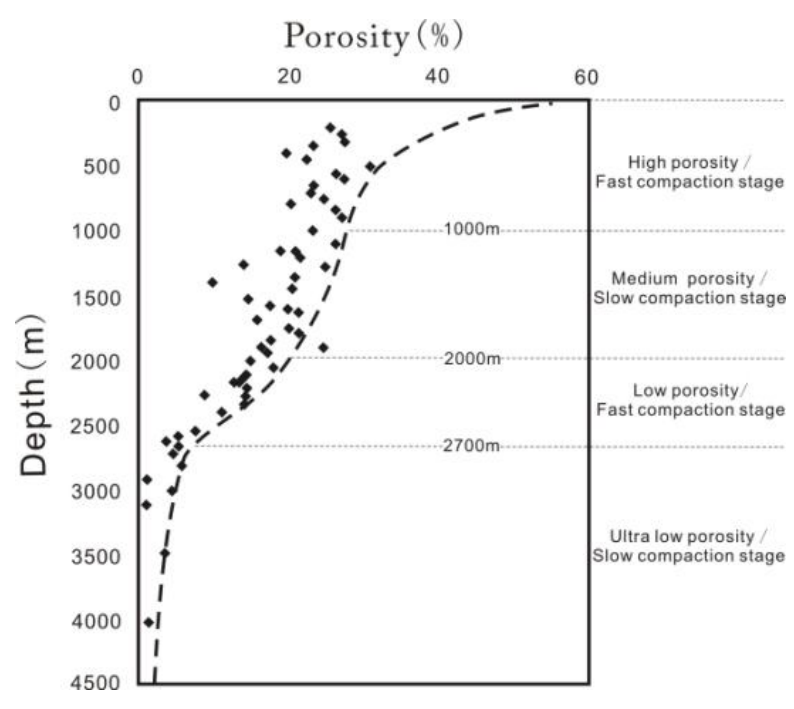

Fig. (6). The relevance between argillite compaction and depth in Jiyang depression. (modified according to Dunxiang Zhang,1979).

Furthermore, a diagram of breakthrough pressure vs. compaction of argillite rock in the Zhanhua Sag was drawn, combined with experimental data from Xuetian Li (1992) and Zongqi Zhu (1996). The results show that the higher the degree of compaction of argillite is, the higher the breakthrough pressure it has, and the better sealing capacity it has. In the same way, the breakthrough pressure was also classified into 4 stages, which respond to the compaction of argillite rock: At stage I, the breakthrough pressure of argillite rock is low, generally 0.1-0.4 MPa. At stage II, its breakthrough pressure has increased, generally to 0.1-12 MPa. At the stage III, the breakthrough pressure is generally 4-12 MPa. At stage IV, its breakthrough pressure increases, generally to 10-25 MPa (see Fig. 7).

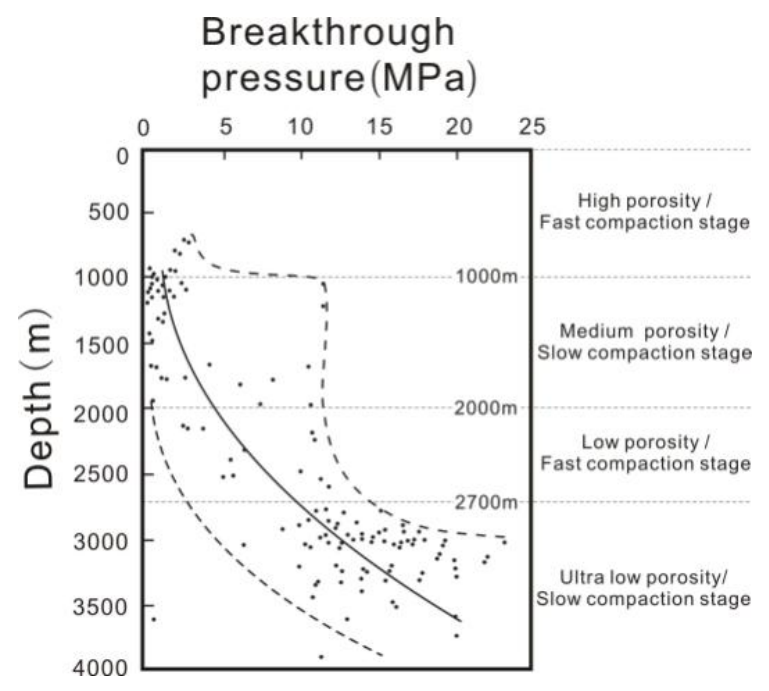

Fig. (7). Relationship between argillite compaction degree and breakthrough pressure in the Zhanhua Sag. (Modified according to Xuetian Li,1992, and Zongqi Zhu, 1996).

Overall, if other factors are ignored, the seal capacity of argillite rock becomes better with the depth increases.

\subsection{Cap Destruction by Fractures}

For highly diagenetic mudstone, good physical parameters generally mean better sealing ability. In this case, two factors play an important role in the evaluating sealing capacity of mudstone, one is the mechanical properties of the cap, the other one is whether it has fractures [38]. In transformation of the latter period of tectonic movements, brittle 
rock can easily format micro-cracks, which weakened sealing capacity [33]. So we performed a research on the fractures through the core observation and found that the fracture is well developed in the Zhanhua sag, and then divided those fractures into three categories: horizontal fractures, nearly vertical fractures, and diagonal fractures (inclination typically greater than $45^{\circ}$ ).

\subsubsection{Horizontal Fractures}

Such fractures are common in the core, and those fractures can be classified into two types: level fractures and slip fractures. The former have no obvious sliding marks on the surface, and the latter refer to a fracture with obvious slippage. The horizontal fractures are of varying widths, and its lengths are generally small, from a few millimetres to more than ten centimetres. It could be observed that these fractures are filled by calcite veins, and some of them have traces of oil and bitumen. Moreover, slip fractures are also very common in the core, and mainly develop on the lithological contact surface. Its width is generally small, and most of them have sliding surface and obvious scratches. (see Fig. 8a).

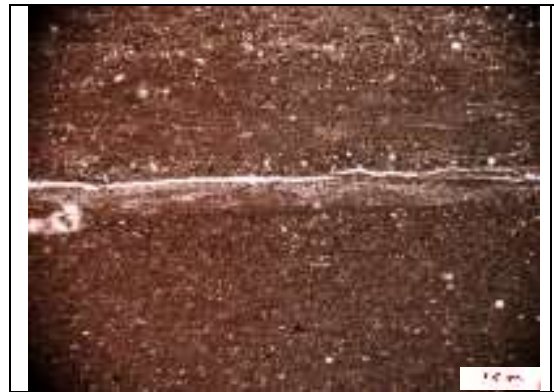

(a) Horizontal fractures, L67, 3316.80 m, MB-11-D-50, polarized light, $50 \times$

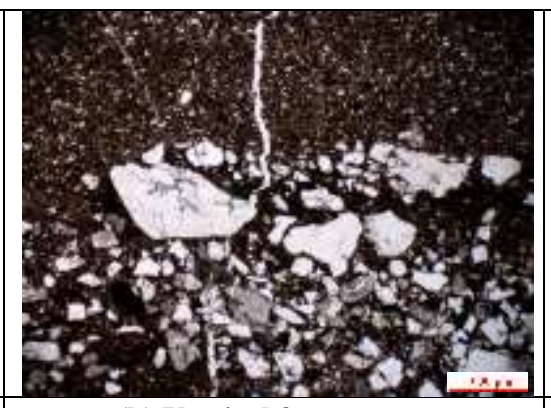

(b) Vertical fractures,

Y3-7-7, 3 S20-D-25-1, polarized light, $25 \times$

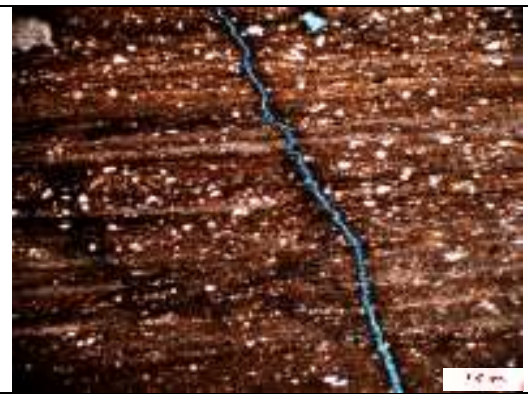

(c) Diagonal fractures,

Y171, 3031.00 m, TJSS3B-D-50-1, polarized light, $50 \times$

Fig. (8). Fractures in argillite rocks of the Zhanhua Sag.

\subsubsection{Vertical Fractures}

Vertical fractures which develop perpendicular to the rock layer are common in the core, with its widths ranging from tenths of a millimetre to several centimetres, and its length ranging from a few millimetres to nearly a metre. Similar to the horizontal fractures, ome of them are filled with white calcite veins, and some of them have traces of oil and bitumen. Those calcite veins are of good crystal form, and most of them contain fine or powder crystalline (see Fig. 8b).

\subsubsection{Diagonal Fractures}

Such fractures are also common in the core, and most of the angle between the fracture and rock layer are very big. Its widths and lengths are quite different, and some of them have sliding characteristics, as well as obvious scratches. The surfaces of those fractures are straight, but some of them are rough. Similarly, it can be observed that some fractures are filled with calcite veins, and some of them have traces of oil and bitumen (see Fig. 8c).

Furthermore, most fractures in the mudstone were found to have depths below $2000 \mathrm{~m}$ according to core observations and statistics on the argillite rocks of the Zhanhua Sag (see Table 1). We roughly divided these fractures into two groups: One is above a depth of approximately $2000 \mathrm{~m}$, where the fracture development is poor, the other is below $2000 \mathrm{~m}$, where fractures are well developed.

Table 1. Depth statistics on argillite fractures of Paleogene-Neogene strata in the Zhanhua Sag.

\begin{tabular}{|c|c|c|c|c|c|}
\hline Well NO. & Depth (m) & $\begin{array}{c}\text { Core length } \\
(\mathbf{m})\end{array}$ & Lithology & Fracture Type & Fracture development \\
\hline CH110 & $1910.62-1911.62$ & 0.95 & mudstone & horizontal fractures & not develop \\
\hline CH110 & $1913.96-1917.27$ & 3.27 & mudstone & hortical fractures & not develop \\
\hline Y99 & $3021.7-3027.8$ & 6.1 & silty mudstone & develop & dertical fractures, horizontal fractures \\
\hline Y99 & $3027.8-3030.7$ & 2.9 & mudstone & develop \\
\hline
\end{tabular}


(Table $\square$ ) contd.....

\begin{tabular}{|c|c|c|c|c|c|}
\hline Well NO. & Depth (m) & $\begin{array}{c}\text { Core length } \\
\text { (m) }\end{array}$ & Lithology & Fracture Type & Fracture development \\
\hline Y3-7-7 & $3093.63-3094.63$ & 0.98 & calcareous mudstone & vertical fractures, diagonal fractures & develop \\
\hline Y3-7-7 & $3104.3-3106.5$ & 2.16 & silty mudstone & vertical fractures & develop \\
\hline Y3-7-7 & $3125.44-3134.34$ & 8.9 & silty mudstone & vertical fractures & develop \\
\hline Y160 & $3130.8-3132.0$ & 1.2 & siliceous mudstone & horizontal fractures & develop \\
\hline Y160 & $3163.03-3169.9$ & 6.87 & shale & horizontal fractures, vertical fractures, diagonal fractures & develop \\
\hline L67 & $3242.0-3250.0$ & 8 & mudstone & horizontal fractures, vertical fractures & develop \\
\hline L67 & $3270.0-3277.28$ & 7.28 & mudstone & $\begin{array}{l}\text { parallel level fractures, vertical fractures, diagonal } \\
\text { fractures }\end{array}$ & develop \\
\hline L67 & $3305.26-3320.0$ & 14.74 & mudstone & horizontal fractures, vertical fractures, diagonal fractures & develop \\
\hline Y3-7-7 & $3323.8-3325.0$ & 1.2 & mudstone & horizontal fractures, vertical fractures & develop \\
\hline Y171 & $3482.0-3482.6$ & 0.6 & silty mudstone & horizontal fractures & develop \\
\hline L67 & $3380.5-3387.55$ & 7.05 & mudstone & horizontal fractures, vertical fractures & develop \\
\hline Y3-7-7 & $3500.54-3505.83$ & 5.29 & silty mudstone & diagonal fractures & develop \\
\hline Y172 & $3525.46-3530.56$ & 5.1 & siliceous mudstone & horizontal fractures, diagonal fractures & develop \\
\hline BS3 & $3533.15-3534.65$ & 1.5 & mudstone & horizontal fractures & develop \\
\hline BS3 & $3544.79-3547.79$ & 3 & mudstone & horizontal fractures, vertical fractures & develop \\
\hline Y160 & $3579.09-3585.21$ & 6.12 & siliceous mudstone & horizontal fractures, vertical fractures, diagonal fractures & develop \\
\hline BS3 & $3733.14-3738.5$ & 2.36 & mudstone & vertical fractures & develop \\
\hline BS3 & $3739.3-3741.64$ & 2.34 & mudstone & vertical fractures & develop \\
\hline Y172 & $3949.80-3950.6$ & 0.8 & siliceous mudstone & $\begin{array}{c}\text { horizontal fractures, } \\
\text { diagonal fractures }\end{array}$ & develop \\
\hline Y172 & 3950.6-3956.0 & 5.4 & siliceous mudstone & horizontal fractures, vertical fractures & develop \\
\hline Y151 & 4032.64-4036.81 & 4.17 & silty mudstone & vertical fractures, diagonal fractures & develop \\
\hline BS4 & $4119.22-4123.22$ & 4 & mudstone & horizontal fractures & develop \\
\hline
\end{tabular}

Overall, fractures are well developed in the Zhanhua sag, which weakened sealing capacity of argillite rock. As a result of most fractures develop below a depth of $2000 \mathrm{~m}$, we think that the sealing is bad below $2000 \mathrm{~m}$, contrarily, it is considered good within $2000 \mathrm{~m}$.

\subsection{Cap Destruction by Faults}

The fault could destroy argillite cap not only from the vertical side but also to a wide range in the plane. Fractures are well developed in the Zhanhua Sag according to the research of Shunxing $\mathrm{Lu}$ (2003) [39]. There are ten large faults that clearly control the deposition which are the LuoXi, GuXi, WuHaoZhuang, YiDong, ChengDong, KenDong, GuBei, GuNan, KenLi and ChengBei faults. In addition, a number of small faults are also developed inside the sag (see Fig. 1). This may have a great impact on the sealing of argillite rock. Therefore, the size of faults and the number of faults, especially the sealing of the faults have great impact on the sealing capacity [40]. This study focuses on the impact of fault-sealing on the cap.

\subsubsection{Fault Activity}

When the fault is active, its sealing is poor and its transportation is favourable. At this point, no matter how the mechanical properties of argillite which is disconnected by faults, or there is formation of gouge or other low permeability filling or not,the sealing of the fault is not good.

\subsubsection{Argillite Rock Mechanical Properties}

We drew a diagram of argillite rock mechanical properties vs. fault sealing in the Zhanhua Sag, and classified both of them into three stages (see Fig. 9). The results indicate that argillite rock mechanical properties have a significant impact on fault sealing: At stage I (less than $1000 \mathrm{~m}$ in depth), when the fault is not active, it is easily closed. At this time, the fault sealing depends on argillite sealing, and its sealing is generally good. At stage II (depth form 1000 to $2000 \mathrm{~m}$ ), when the fault is not active, it is not easy to close due to the strong rigidity of argillite. In other words, it is easy to maintain. In this case, fault sealing depends on the degree of development of the fractures, and its sealing is usually poor. At stage III (deeper than $2000 \mathrm{~m}$ ), similarly to stage II, the fault is not easy to close when it is not active. Moreover, the argillite whose fractures are well developed will be affected by faults again, and fractures will be further developed. Thus, the sealing of the fault will become worse. 


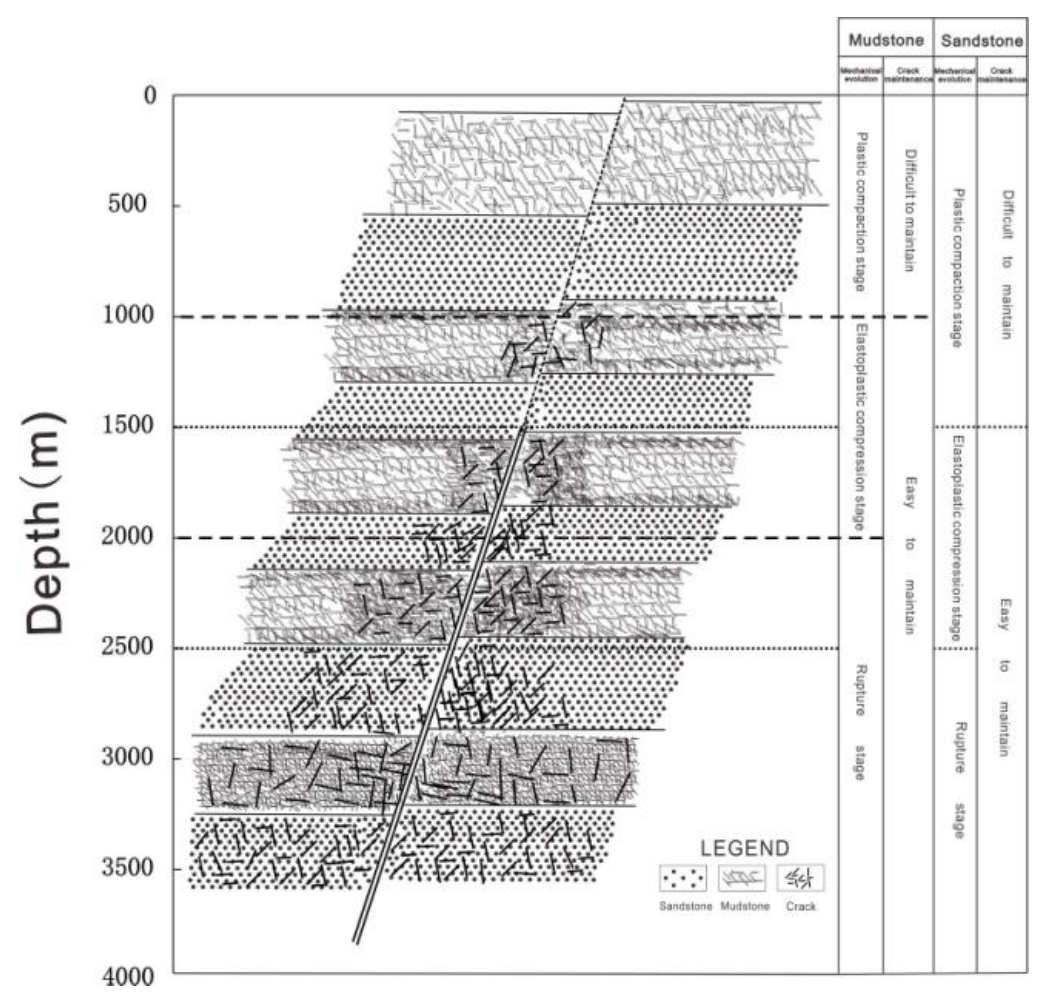

Fig. (9). Argillite rock mechanics stages and fault sealing capacity.

If we observe the faults of different strata as inactive faults, fault sealing is relevant to the mechanics stage of argillite rock. Therefore, we classified the faults into 3 stages, which respond to the argillite rock mechanics (see Fig. 9). The fault sealing capacity is good at stage I, and it becomes bad at stage II and III. At stage III, its sealing capacity is the worst.

\subsection{Types of Argillite Cap and its Distribution}

\subsubsection{Types of Argillite Cap}

Through the above analysis, the higher the compaction degree of argillite rock is, the better sealing capacity it has. However, its sealing capacity could be destroyed by fractures and faults, especially below 2000m, where fractures are well developed and faults are not easy to close. Therefore, we classified the argillite cap into three categories: porosity cap, fracture transformation cap and fault transformation cap (see Table 2). Firstly, the porosity cap, mainly refer to argillaceous sedimentary caps, where the porosity is mainly affected by compaction and without destruction by fractures or faults. Secondly, the fracture transformation cap, mainly refers to cap destroyed by fractures. At last, the fault transformation cap, mainly refers to cap destroyed by faults. Among their sealing capacity, the porosity cap is the best, followed by the fracture transformation cap, and the fault transformation cap is the worst.

Table 2. Types of argillite cap and its characteristics of Paleogene-Neogene strata in the Zhanhua Sag.

\begin{tabular}{|c|c|c|c|c|c|c|}
\hline \multicolumn{3}{|c|}{ Features and sealing capacity of each category } & \multicolumn{4}{|c|}{ Features and sealing capacity of subcategories } \\
\hline Types & Features & Sealing capacity & Sub-categories & Features & Sealin & capacity \\
\hline \multirow{3}{*}{ Porosity cap } & \multirow{3}{*}{$\begin{array}{c}\text { argillaceous } \\
\text { sedimentary, mainly } \\
\text { through compaction, } \\
\text { and without fractures or } \\
\text { faults destruction }\end{array}$} & \multirow{3}{*}{ Overall good } & High porosity & Porosity more than $23 \%$ & Good & \multirow{3}{*}{$\begin{array}{c}\text { Mostly good } \\
\text { with some } \\
\text { bad }\end{array}$} \\
\hline & & & Medium porosity & $\begin{array}{c}\text { Porosity from } \\
20 \%-23 \%\end{array}$ & Better & \\
\hline & & & Low to Ultra-Low porosity & Porosity less than $20 \%$ & Best & \\
\hline $\begin{array}{c}\text { Fracture } \\
\text { transformation cap }\end{array}$ & destruction by fractures & $\begin{array}{c}\text { Partial } \\
\text { destruction }\end{array}$ & Fracture transformation cap & & $\begin{array}{l}\text { Worse in } \\
\text { fractures }\end{array}$ & $\begin{array}{l}\text { Good and } \\
\text { bad }\end{array}$ \\
\hline \multirow{3}{*}{$\begin{array}{c}\text { Fault transformation } \\
\text { cap }\end{array}$} & \multirow{3}{*}{ destruction by faults } & \multirow{3}{*}{$\begin{array}{l}\text { Large-scale } \\
\text { destruction }\end{array}$} & $\begin{array}{c}\text { plastic Fault transformation } \\
\text { cap }\end{array}$ & $\begin{array}{l}\text { Plastic compaction } \\
\text { stage }\end{array}$ & Good & \multirow{3}{*}{$\begin{array}{l}\text { Mostly bad } \\
\text { with some } \\
\text { good }\end{array}$} \\
\hline & & & $\begin{array}{l}\text { elastoplastic fault } \\
\text { transformation cap }\end{array}$ & $\begin{array}{c}\text { Elastoplastic } \\
\text { compression stage }\end{array}$ & $\mathrm{Bad}$ & \\
\hline & & & $\begin{array}{l}\text { rupture fault transformation } \\
\text { cap }\end{array}$ & Ruputure stage & worst & \\
\hline
\end{tabular}


The porosity cap can be further classified into three subcategories according to the degree of argillite compaction: (1) high porosity cap, whose depths are less than $1000 \mathrm{~m}$, refers to an argillite cap with high porosity and at fast compaction stage, its depths from 0 to $1000 \mathrm{~m}$; (2) medium porosity cap, whose depths are from 1000 to $2000 \mathrm{~m}$, refers to an argillite cap with medium porosity and at slow compaction stage; (3) low to ultra-low porosity cap, whose depths are more than $2000 \mathrm{~m}$, refers to an argillite cap with the low to ultra-low porosity and at fast or slow compaction stages. Its sealing capacity is generally good, and among them the third subcategory is the best.

Similarly, Fault transformation cap can also be further classified into three subcategories according to the argillite rock mechanics stages: (1) plastic fault transformation cap, whose depths are less than 1000m, refers to the fault is in a plastic compaction stage of argillite rock; (2) elastoplastic fault transformation cap, whose depths are from 1000 to $2000 \mathrm{~m}$, refers to the fault is in an elastoplastic compression stage of argillite rock; (3) rupture fault transformation cap, whose depths are more than $2000 \mathrm{~m}$, refers to the fault is in a rupture stage of argillite rock. Its sealing capacity is generally bad, and the rupture fault transformation cap is the worst.

\subsubsection{Argillite Cap Distribution}

The above classification focuses on each single factor; in fact, the sealing capacity of each argillite cap is not only affected by its compaction, but also by its destruction by the fractures and faults at the same time. Based on this, we classified the argillite cap into three combination zones in the vertical direction: Class I, with the depth from 0 to 1000 $\mathrm{m}$, refers to the high porosity, and plastic fault transformation cap combination zone, where its sealing capacity is good overall; Class II, with the depth from 1000 to $2000 \mathrm{~m}$, refers to the medium porosity, and elastoplastic fault transformation cap combination zone, where its sealing capacity is better overall, but locally is worse; Class III, with the depth more than $2000 \mathrm{~m}$, refers to the low to ultra-low porosity, and fracture transformation cap to rupture fault transformation cap combination zone, where its sealing capacity varies, may be good or bad (see Table 3).

Table 3. Argillite cap types of Paleogene-Neogene strata in thevertical direction.

\begin{tabular}{|c|c|c|c|}
\hline Types & Depth(m) & Features & Sealing capacity \\
\hline Class I & $<1000$ & high porosity, plastic fault transformation cap combination zone & Good \\
\hline Class II & $1000-2000$ & medium porosity, elastoplastic fault transformation cap combination zone & Better, locally worse \\
\hline Class III & $>2000$ & low to ultra-low porosity, fracture transformation cap to rupture fault transformation cap combination & zone \\
\hline
\end{tabular}

We drew a plane graph of cap distribution of Paleogene-Neogene in the Zhanhua Sag according to the above cap classifications and combinations, and selected the $\mathrm{Ng}$ and Es2 cap distributions as explanations (see Fig. 10 and Fig. 11)

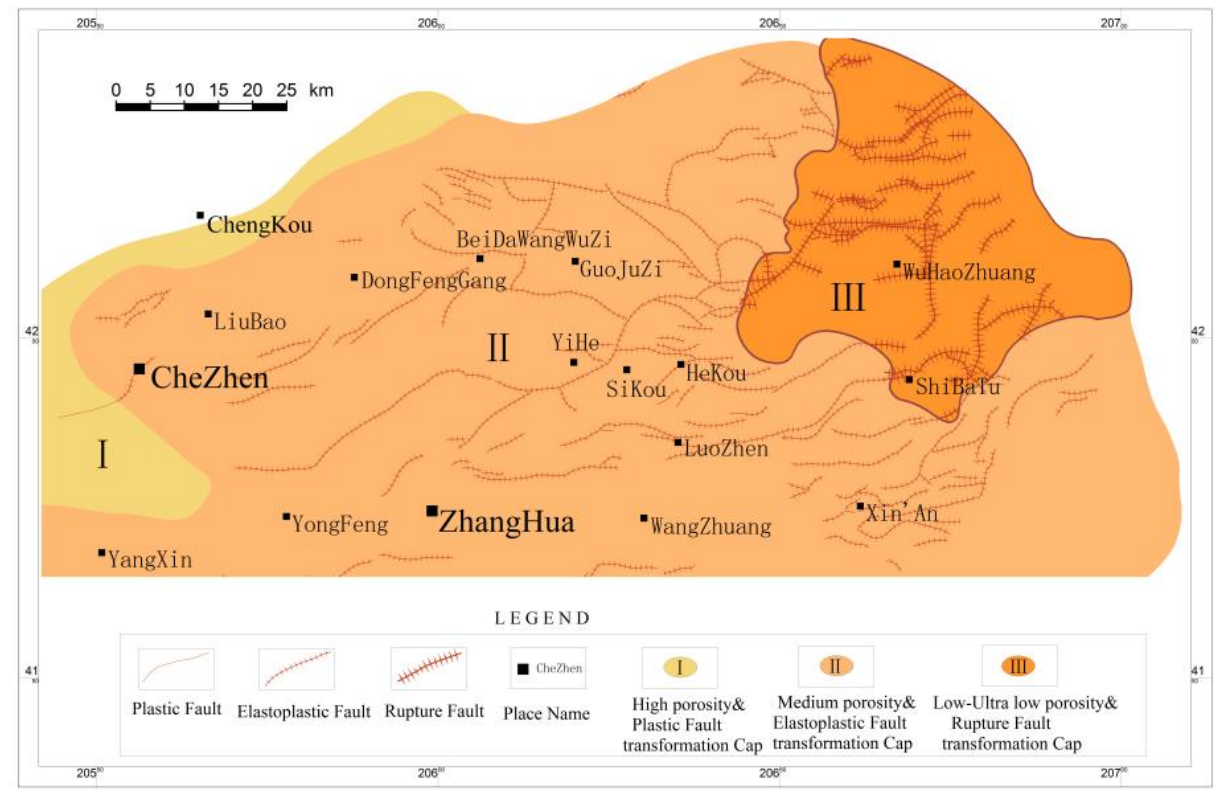

Fig. (10). Argillite cap of the Ng stratum: types and plane distribution in the Zhanhua Sag. 


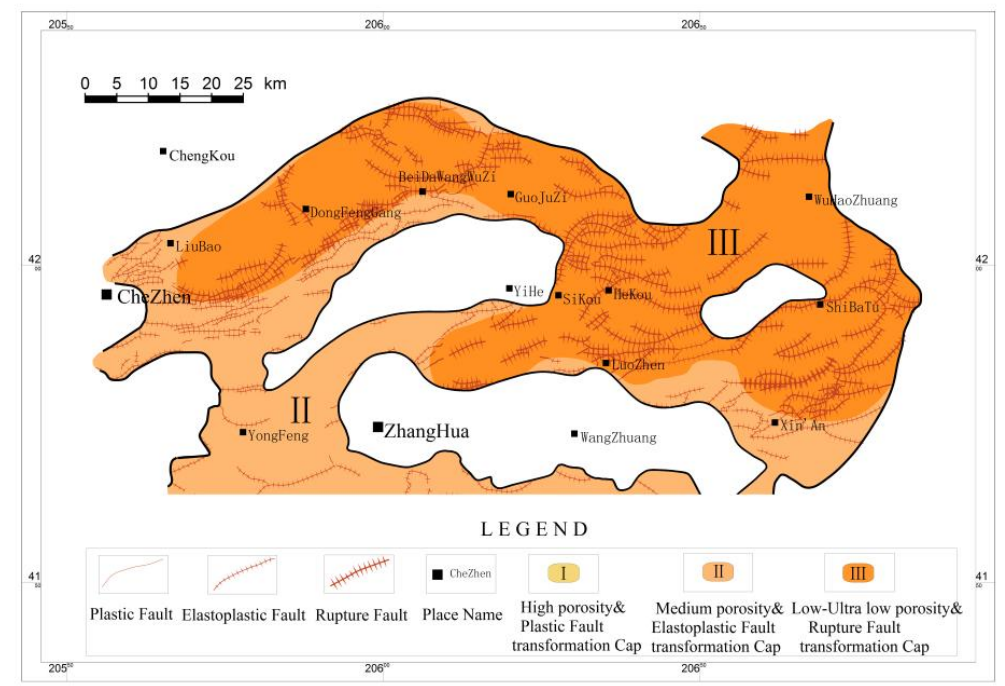

Fig. (11). Argillite cap of the Es2 stratum: types and plane distribution in the Zhanhua Sag.

Fig. (10) shows that Class I, II, and III cap combinations are all developed in the Ng stratum of the Zhanhua Sag. Large area developed Class II cap combination in the middle, and the Class III cap combination mainly develop in the northeast of the Sag. In contrast, just a small part of the western region developed a Class I cap combination.

Fig. (11) shows that only II and III cap combinations are developed in the Es2 stratum of the Zhanhua Sag, and it is obvious that the Class III is the main type, for large area this cap combination is developed in the northeast of the sag, and Class II cap combination is developed in the middle. However, Class I cap combination is lacked.

\section{RELATIONSHIP BETWEEN CAP ROCK AND HYDROCARBON ACCUMULATION}

\subsection{Relationship Between Argillite Cap and the Existing Oil and Gas Reservoir}

Based on the above research, we have a clear understanding of the distribution of caprock types in each stratum. Furthermore, we put the existing oil and gas reservoir into the plane graph of cap distribution, and analyzed the relationship between cap and hydrocarbon accumulation. Similarly, the Ng and Es2 are selected. The results show that most oil and gas reservoirs of $\mathrm{Ng}$ stratum are located in the transfer belts of III to II. Above the transfer belt, the Nm is a Class II cap combination. However, below this transfer belt, the caps of Ed, Es1, Es2, Es3 stratum are all Class III cap combinations (see Fig. 12). Obviously, the sealing capacity of Class III cap combinations is better than that of Class II according to the previous study, thus leading to oil and gas accumulation.

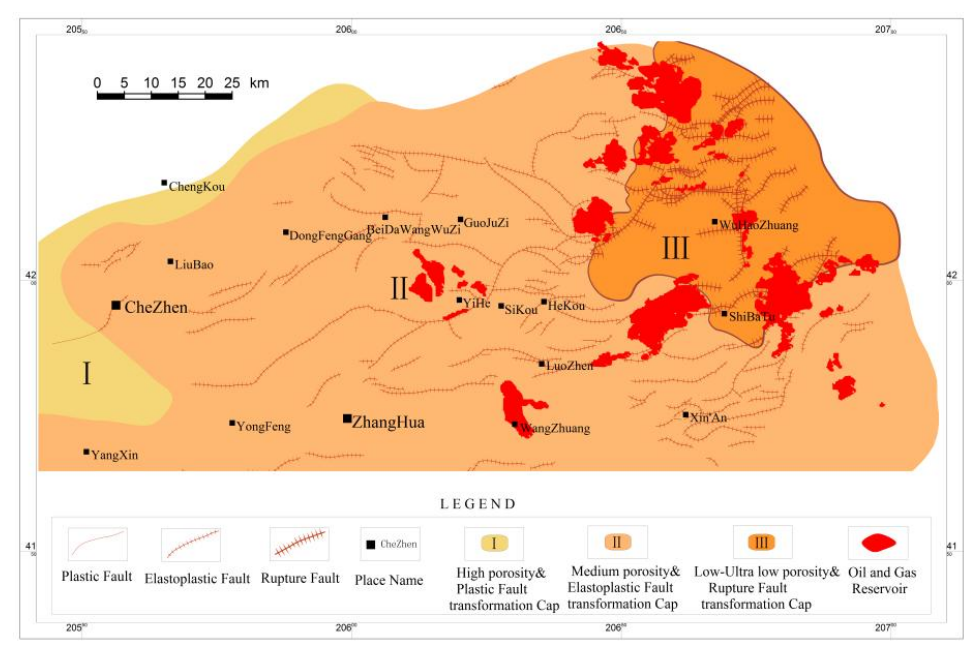

Fig. (12). Relationship between cap and oil and gas reservoirs in the $\mathrm{Ng}$ of the Zhanhua Sag. 
In the same way, we found that most oil and gas reservoirs of $\mathrm{Es}_{2}$ stratum are located in the transfer belt of the rupture fault transformation cap to fracture transformation cap. Above the transfer belt are the Es $s_{1}$ and Ed strata, where mainly Class III cap combinations are developed. Below this transfer belt is Es $_{3}$ stratum, and it is also a Class III cap combination (see Fig. 13).

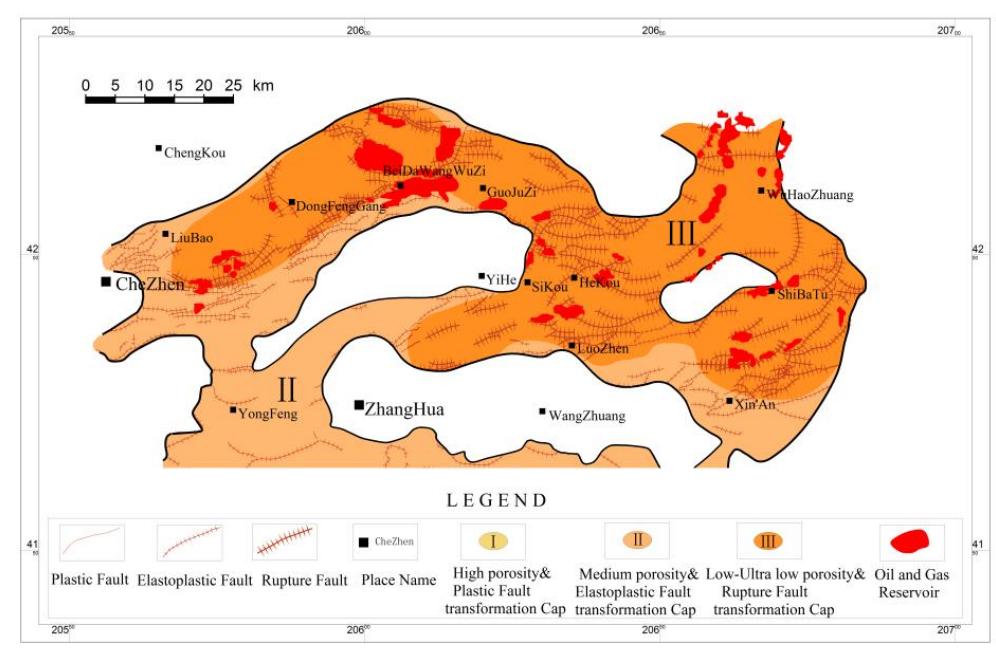

Fig. (13). Relationship between cap and oil and gas reservoirs in the $\mathrm{Es}_{2}$ of the Zhanhua Sag.

\subsection{Relevance Between Argillite Cap and Hydrocarbon Accumulation and Preservation}

Through the above analysis on the relationship between existing oil \& gas reservoirs and the plane distribution characteristics of the Paleogene-Neogene cap in the Zhanhua Sag, it was found that the cap combination which is below or above the reservoir together control the hydrocarbon accumulation and preservation. The destruction of the cap below or down-dip the reservoir is a necessary condition for hydrocarbon accumulation, and only when the sealing capacity of the cap rock above or up-dip the reservoir is better than that of below or down-dip, oil \& gas could be efficiently stored in reservoirs, thus could be effectively enriched.

Based on that, Fig. (14) was drawn to show the hydrocarbon accumulation and preservation of the porosity cap and fracture transformation cap. It can be seen that hydrocarbon most likely accumulates in reservoirs of the transition zone, when in the porosity cap and the fracture transformation cap composition system. However, when both above and below the reservoir is a porosity cap, oil \& gas could not accumulate, and when both above and below the reservoir is fracture transformation caps, oil \& gas can partly accumulate (see Fig. 14).

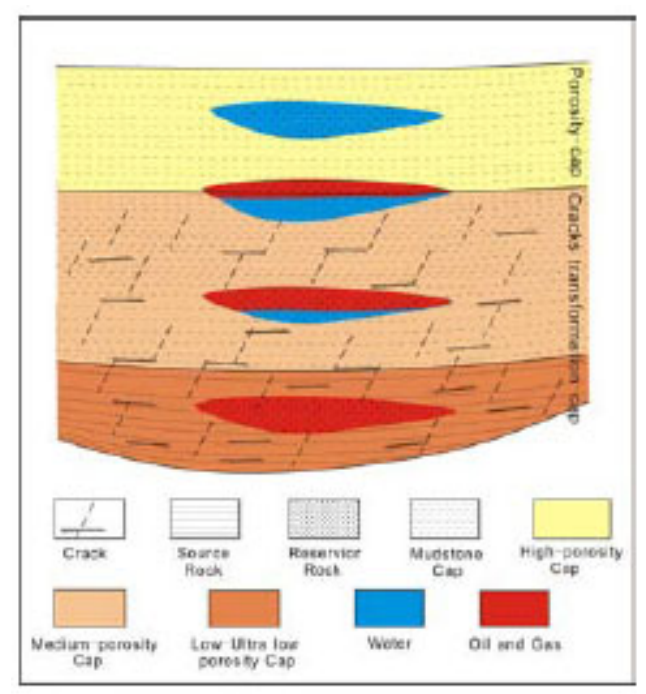

Fig. (14). Hydrocarbon accumulation and preservation in the porosity cap and fracture transformation cap. 
Fig. (15) show that in the system of three cap types, the following combinations make it easy and effective for the reservoir to accumulate and preserve oil \& gas: the transition belt of fault transformation cap and fracture transformation cap; the transition belt of fault transformation cap and porosity cap; the transition belt of rupture fault transformation cap and elastoplastic fault transformation cap; and the transition belt of elastoplastic fault transformation cap and plastic fault transformation cap (see Fig. 15).

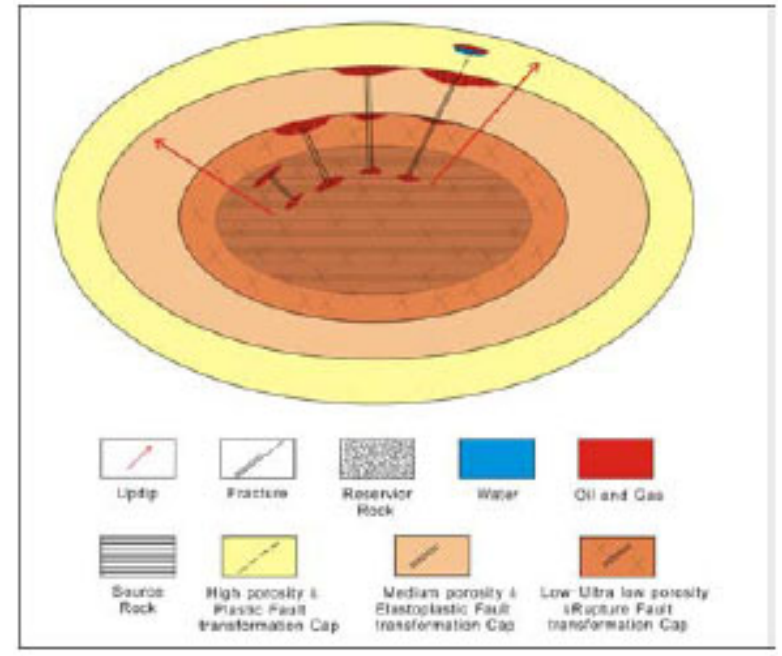

Fig. (15). Hydrocarbon accumulation and preservation in a reservoir system consisting of a porosity cap, a fracture transformation cap, and a fault transformation cap.

In short, the cap above or up-dip the reservoir has effective sealing, that means the sealing capacity is better than that of below or down-dip the reservoir, is an important factor in controlling hydrocarbon accumulation.

\section{CONCLUSION}

Four types of cap rock are found in the Zhanhua Sag: argillite rock and silty mudstone, microcrystalline carbonate, dense cemented sandstone and dense cemented carbonate. Among them, argillite rock is the main type of the cap rock in the Zhanhua Sag.

The higher the degree of compaction of the argillite rock has, the higher breakthrough pressure it has, and better sealing capacity it has. When fractures develop in the cap rock, its sealing capacity will be partly destroyed. Similarly, faults could destroy the argillite cap not only from the vertical side but also to a wide range of the plane. Through the analysis of its compaction and its destruction by fractures and faults, the argillite cap can be classified into three categories: porosity cap, fracture transformation cap and the fault transformation cap. Among their sealing capacity, the porosity cap is the best, followed by the fracture transformation cap, and the fault transformation cap is the worst.

Furthermore, argillite cap is classified the into three combination zones in the vertical direction: Class I, with the depth from 0 to $1000 \mathrm{~m}$, refers to the high porosity, and plastic fault transformation cap combination zone, where its sealing capacity is overall good; Class II, with the depth from 1000 to $2000 \mathrm{~m}$, refers to the medium porosity, and elastoplastic fault transformation cap combination zone, where its sealing capacity is better, but locally of which is worse; Class III, with the depth more than $2000 \mathrm{~m}$, refers to the low to ultra-low porosity, and fracture transformation cap to rupture fault transformation cap combination zone, where its sealing capacity varies, may be good or bad.

Through the analysis of the relationship between existing oil \& gas reservoirs and the distribution characteristics of the Paleogene-Neogene cap rock in the Zhanhua Sag, it is found that the cap combination which is below or above the reservoir together control the hydrocarbon accumulation and preservation. The cap rock above or up-dip the reservoir has effective sealing that means the sealing capacity is better than that of below or down-dip the reservoir, is an important factor in controlling hydrocarbon accumulation.

\section{CONFLICT OF INTEREST}

The authors confirm that this article content has no conflict of interest. 


\section{ACKNOWLEDGEMENTS}

We would like to acknowledge the reviewers and the editors for their many helpful comments and suggestions. Thanks to Shoupeng Zhang, deputy chief geological engineer of Sinopec Group, Dr. Guiqiang Qiu who came from RIPED, as well as Ning Liu, Jianbin Teng and Lijuan Yin. This work was financially supported by the Basic geological survey project of China Geological Survey (ID:12120113040700) and National Natural Science Foundation of China (ID: 41372129).

\section{REFERENCES}

[1] K.H. Xiao, Y.J. Wo, Y. Zhou, and H.Q. Tian, "Petroleum reservoiring characteristics and exploration direction in marine strata in southern China", Oil and Gas Geology, vol. 27, no. 3, pp. 316-325, 2006.

[2] X. Liang, Z. Ye, K.D. Xu, S.H. Wu, Y.S. Zhang, and J.Z. Liu, "Matine petroleum superSystems in Southern China", Gas Industry, vol. 25, no. 2, pp. 1-5, 2005.

[3] M.C. Li, W. Li, F. Cai, and D.M. Sun, "Integrative study of preservation conditions of oil and gas pools", Acta Petroleisin Ica, vol. 18, no. 2, pp. 41-48, 1997.

[4] R.H. Dott, and M.J. Reynolds, "Source book for petroleum geology. Tulsa", AAPG Memoir, vol. 5, p. $471,1969$.

[5] M.C. Li, W.C. Li, and S.D. Feng, "Integrative study of preservation conditions of oil and gas pools", Acta Pet., vol. 18, pp. $41-48$, 1997.

[6] G. Fu, Z.M. Chen, and Z.X. Jiang, "Evaluation of the sealing ability of caprock and its application", Petroleum Exploration and Development, vol. 22 , no. 3 , pp. 46-50, 1995.

[7] L.H. Hou, Z.R. Liu, and J.H. Wang, "Quantitative evaluation method for sealproperty of cap formation", Journal of Univiersity of Petroleum, vol. 20, pp. 1-4, 1996 .

[8] Z.Y. Deng, S.C. Wang, and Z.N. Chen, "Breaking pressure of gas cap rocks", Oil and Gas Geology, vol. 21, pp. 136-138, 2000.

[9] Z.Y. Chen, Z.W. Zhang, G. Zhang, L.L. Zhu, and Z.Y. Zhen, "Natural gas capping performance explore in Southern Liaoning", Natural Gas Geoscience, vol. 6, pp. 18-23, 1955.

[10] Y.M. Tan, L.Y. Ren, H.A. Zhang, J.B. Zhang, J.Z. Xu, and Z.H. Jin, "Comprehensive evalution of sealing capacity of claystone in deep cas reservoir", Oil and Gas Geology, vol. 24, pp. 191-195, 2003.

[11] D.W. Zhen, "Establish evaluation for criteria Capillary seal gas cap", Natural Gas Geoscience, vol. 23, pp. 29-33, 1994.

[12] P.G. Ren, J.G. Pan, K.J. Tan, L. Yin, and J.J. Zhang, "The research of gas caprock in ZhongGuai-WuBa zone of Junggar Basin", Xinjiang Oil \& Gas, vol. 3, pp. 24-28, 2007.

[13] Z.L. Huang, and S.S. Hao, "A method estimating breakthough pressure and displacement pressure of caprock", Xinjiang Petroleum Geology, vol. 15 , pp. 163-166, 1994 .

[14] Y.F. Lyu, G. Fu, and D.L. Gao, The Reservoir Cap Rock Research., Petroleum Industry Press: Beijing, 1996 , p. 30.

[15] L.Y. Zhang, Y.S. Bao, and Q. Liu, "Effects of hydrocarbon physical properties on caprock's sealing ability", China Earth, vol. 40, no. 1, pp. 28-33, 2010.

[16] G. Fu, Z. Chen, and Lv. Yanfang, "Comprehensive evaluation of sealing ability of mudstone caprock", Experimental Petroleum Geology, vol. 20, no. 1 , pp. 80-86, 1998 .

[17] A Gartrell, W R Bailey, and M. Brincat, "A new model for assessing trap integrity and oil preservation risks associated with post-rift fault reactivation in the Timor Sea", AAPG Bulletin, vol. 90, no. 12, pp. 1921-1944, 2006.

[18] M.W. Downey, "Evaluating seals for hydrocarbon accumulations", AAPG Bulletin, vol. 68, pp. 1752-1763, 1984.

[19] H.R. Grunau, "A worldwide look at the cap rock problem", J. Pet. Geol., vol. 10, pp. 245-266, 1987. [http://dx.doi.org/10.1111/j.1747-5457.1987.tb00945.x]

[20] M. Timlin, Effects of stratigraphy on geothermal reservoir performance. AAPG Annual Convention and Exhibition, vol 06, pp. 7-10, 2009.

[21] S. Corrado, L. Aldega, A.S. Celano, A.A. De Benedetti, and G. Giordano, "Cap rock efficiency and fluid Circulation of natural hydrothermal systems by means of XRD on clay minerals (Sutri, Northern Latium,Italy)", Geothermics, vol. 50, pp. 180-188, 2014. [http://dx.doi.org/10.1016/j.geothermics.2013.09.011]

[22] M.L. Carapezza, M. Ranaldi, A. Gattuso, N.M. Pagliuca, and L. Tarchini, "The sealing capacity of the cap rock above the Torre Alfina geothermal reservoir(Central Italy) revealed by soil CO2 flux investigations", Journal of Volcanology and Geothermal Research, vol. 291, pp. 25-34, 2015.

[http://dx.doi.org/10.1016/j.jvolgeores.2014.12.011]

[23] D.A. Smith, "Sealing and non sealing faults in louisiana gulf coast salt basing", AAPG Bulletin, vol. 64, no. 2, pp. 145-172, 1980.

[24] L. Yanfang, G. Li, and Y. Wang, "Quantitative analyses in fault sealing properties", Acta Petrolei Sinica, vol. 17, no. 3, pp. 39-45, 1996.

[25] D.A. Smith, "Theoretical consideration of sealing and non sealing faults", American Association of Petroleum Geologists Bulletin, vol. 50, no. 2, pp. 363-374, 1996. 
[26] J.J. Shi, L.L. Li, G. Fu, Y.F. Lv, and W.Y. Jiang, "Quantitative evaluation method and application of vertical sealing property of faults in caprock", Journal of Jilin University, vol. 42, no. 2, pp. 162-170, 2012. [Earth Science Edition].

[27] B.M. Krooss, D. Leythaeuser, and R.G. Schaefer, "Experimental determination of diffusion parameters for light hydrocarbons in watersaturated rocks: some selected results", Org. Geochem., vol. 10, pp. 291-297, 1986. [http://dx.doi.org/10.1016/0146-6380(86)90030-6]

[28] N.L. Watts, "Theoretical aspects of cap-rock and fault seals for single-and two-phase hydrocarbon columns", Mar. Pet. Geol., vol. 4, pp. 274-307, 1987. [http://dx.doi.org/10.1016/0264-8172(87)90008-0]

[29] S.J. Roberts, and J.A. Nunn, "Episodic uid expulsion from geopressured sediments", Mar. Pet. Geol., vol. 12, pp. 195-202, 1995. [http://dx.doi.org/10.1016/0264-8172(95)92839-O]

[30] G.M. Ingram, J.L. Urai, and M.A. Naylor, "Sealing processes and top seal assess-ment", Norwegian Petroleum Society Special Publications, vol. 7, pp. 165-174, 1997. [http://dx.doi.org/10.1016/S0928-8937(97)80014-8]

[31] D.N. Dewhurst, Y. Yang, and A.C. Aplin, "Permeability and uid ow in natural mudstones", Geological Society, London, Special Publications, vol. 158 , pp. $23-43,1999$. [http://dx.doi.org/10.1144/GSL.SP.1999.158.01.03]

[32] T. Zhang, and B.M. Krooss, "Experimental investigation on the carbon isotopefractionation of methane during gas migration by diffusion through sedimentary rocks at elevated temperature and pressure", Geochim. Cosmochim. Acta, vol. 65, pp. 2723-2742, 2001. [http://dx.doi.org/10.1016/S0016-7037(01)00601-9]

[33] Y.S. Yuan, M. Fan, and W.X. Liu, "Several discussions of seraling capacity studies of capock", Petroleum Gealogy \& Experiment, vol. 33, no. 4, pp. 336-339, 347, 2011

[34] X.T. Li, "Discussion on the influential factors over the quality of natural-Gas caprocks and the time of the caprock formation", Petroleum Gealogy \& Experiment, vol. 14, no. 3, pp. 282-290, 1992.

[35] G. Fu, S.C. Zhang, and H.F. Liu, "Use seismic data to study the sealing ability of caprock", Geophysical Prospecting for Petroleum, vol. 35, no. 4, pp. 97-105, 1996

[36] X.L. You, "Study on assessment method of caprocks in natural gas pools", Oil \& Gas Geology, vol. 12, no. 3, pp. 261-275, 1991.

[37] X.B. Wang, J. Li, D.L. Wang, G.Y. Hu, and J.H. Fang, "Research progress and development trend of natural gas caprock", Xinjiang Petroleum Geology, vol. 31, no. 6, pp. 664-668, 2010.

[38] J.Z. Qin, W.X. Liu, M. Fan, W.T. Zhang, and L.J. Yu, "Shale research progress and achievements in seal appraisal technology", Petroleum Gealogy \& Experiment, vol. 35, no. 6, pp. 689-706, 2013.

[39] S.X. Lu, Tectonic Evolution in Eastern of Zhanhua Sag., Ocean University of China: ShanDong, 2003 , pp. 1-35.

[40] J.J. Shi, L.L. Li, Y.F. Lv, J. Yang, and S.Y. Li, "Comrehensive evaluation on the sealing capability of cap rocks in tight sandstone gasfield--a case study from Guang'an gasfield in the Sichuan Basin", Oil \& Gas Geology, vol. 34, no. 3, pp. 307-313, 2013.

C Wu et al.; Licensee Bentham Open

This is an open access article licensed under the terms of the Creative Commons Attribution-Non-Commercial 4.0 International Public License (CC BY-NC 4.0) (https://creativecommons.org/licenses/by-nc/4.0/legalcode), which permits unrestricted, non-commercial use, distribution and reproduction in any medium, provided the work is properly cited. 